\title{
Molecular Dications in Planetary Atmospheric Escape
}

\author{
Stefano Falcinelli ${ }^{1}$,* Fernando Pirani ${ }^{2}$, Michele Alagia ${ }^{3}$, Luca Schio ${ }^{3}$, Robert Richter ${ }^{4}$, \\ Stefano Stranges ${ }^{3,5}$, Nadia Balucani ${ }^{2}$ and Franco Vecchiocattivi ${ }^{1}$ \\ 1 Department of Civil and Environmental Engineering, University of Perugia, Via G. Duranti 93, \\ 06125 Perugia, Italy; franco@vecchio.it \\ 2 Department of Chemistry, Biology and Biotechnologies, University of Perugia, Via Elce di Sotto, \\ 06123 Perugia, Italy; fernando.pirani@unipg.it (F.P.); nadia.balucani@unipg.it (N.B.) \\ 3 IOM-CNR Tasc, Km 163.5, Area Science Park, Basovizza, 34149 Trieste, Italy; \\ michele.alagia@elettra.eu (M.A.); luca.schio90@gmail.com (L.S.); stefano.stranges@uniroma1.it (S.S.) \\ 4 Elettra-Sincrotrone Trieste, Area Science Park, Basovizza, 34149 Trieste, Italy; robert.richter@elettra.eu \\ 5 Department of Chemistry and Drug Technology, University of Rome "La Sapienza", 00185 Rome, Italy \\ * Correspondence: stefano.falcinelli@unipg.it; Tel.: +39-75-585-3856
}

Academic Editor: Robert W. Talbot

Received: 1 August 2016; Accepted: 23 August 2016; Published: 26 August 2016

\begin{abstract}
Fundamental properties of multiply charged molecular ions, such as energetics, structure, stability, lifetime and fragmentation dynamics, are relevant to understand and model the behavior of gaseous plasmas as well as ionosphere and astrophysical environments. Experimental determinations of the Kinetic Energy Released (KER) for ions originating from dissociations reactions, induced by Coulomb explosion of doubly charged molecular ions (molecular dications) produced by double photoionization of $\mathrm{CO}_{2}, \mathrm{~N}_{2} \mathrm{O}$ and $\mathrm{C}_{2} \mathrm{H}_{2}$ molecules of interest in planetary atmospheres, are reported. The KER measurement as a function of the ultraviolet (UV) photon energy in the range of 28-65 eV was extracted from the electron-ion-ion coincidence spectra obtained by using tunable synchrotron radiation coupled with ion imaging techniques at the ELETTRA Synchrotron Light Laboratory Trieste, Italy. These experiments, coupled with a computational analysis based on a Monte Carlo trajectory simulation, allow assessing the probability of escape for simple ionic species in the upper atmosphere of Mars, Venus and Titan. The measured KER in the case of $\mathrm{H}^{+}, \mathrm{C}^{+}, \mathrm{CH}^{+}, \mathrm{CH}_{2}{ }^{+}, \mathrm{N}^{+}, \mathrm{O}^{+}, \mathrm{CO}^{+}, \mathrm{N}_{2}{ }^{+}$ and $\mathrm{NO}^{+}$fragment ions range between 1.0 and $5.5 \mathrm{eV}$, being large enough to allow these ionic species to participate in the atmospheric escape from such planets into space. In the case of Mars, we suggest a possible explanation for the observed behavior of the $\mathrm{O}^{+}$and $\mathrm{CO}_{2}{ }^{2+}$ ion density profiles.
\end{abstract}

Keywords: molecular dications; astrochemistry; planetary atmospheres; ionospheres; synchrotron radiation; ions escape; mass spectrometry; coincidence technique; ion imaging

\section{Introduction}

Gas phase ionization processes induced by energetic photons, electrons or by excited metastable neutral species (also called collisional autoionization reactions [1,2]) play an important role in several phenomena occurring in low energy ionized plasmas and electric discharges $[3,4]$. Furthermore, ionic species are extremely important in the upper atmosphere of planets, where they govern the chemistry of ionospheres [5,6]. In particular, the ionosphere chemistry of Titan has recently been revealed to be extremely active by the instruments on board Cassini $[7,8]$. Finally, molecular ions have also been detected in comet tails [9].

In space, ions are formed in various ways, the importance of which depends on the specific conditions of the extraterrestrial environment considered [10-12]. The interaction of neutral molecules with cosmic rays, UV photons, X-rays and other phenomena such as shock waves are all important processes for their production. In particular, the absorption of UV photons with an energy content 
higher than the ionization potential of the absorbing species can induce ionization with the formation of both singly and doubly charged ions. In the latter case, we have the so-called molecular dications. The reader can refer to some interesting recent review papers by Alagia et al. [6] and by Sabzyan et al. [13] in order to have an overview of the main characteristics and the importance of such doubly charged species. These ionic species can be produced by different techniques, such as mass spectrometry [14], ion-molecule reactions [15], and double photoionization processes [16-19]. In such a field, the importance of a number of experimental and theoretical works conducted by Eland and coworkers [20-22] and by Hochlaf et al. [23,24] concerning the molecules of interest in the present paper must be noted. The molecular dications can be stable or metastable $[14,25]$ and can be used, in principle, as energy storage at a molecular level $[14,15,26]$. Multiply charged ionic species can also be produced by cosmic rays, which are significant since they are ubiquitous and carry a high energy content (up to $100 \mathrm{GeV}$ ). They consist of protons, alpha particles, electrons, $\gamma$-rays and (to a small extent) also heavier nuclei (such as $\mathrm{C}^{6+}$ ). Furthermore, single or double ionization can also occur by absorption of X-rays. In this case, the ejection of a core electron followed by the Auger emission of another electron produces molecular dications, which have been suggested to play a role in the envelope of young stellar objects [27] and upper planetary atmospheres [28-31]. Therefore, molecular dications have recently attracted the attention of the scientific community in order to investigate their possible role in the upper planetary atmospheres. Moreover, molecular $\mathrm{N}_{2}{ }^{2+}$ and $\mathrm{CO}_{2}{ }^{2+}$ dications have been predicted to exist with significant densities in Mars, Venus and Titan (the largest moon of Saturn) ionospheres by Alcaraz and coworkers [32-34]. In fact, molecular dications can be produced in very stable electronic states that allow them to survive several seconds, a lifetime compatible with collision events in such rarefied environments because the typical time between collisions at altitudes corresponding to the peak ionic density of planetary ionospheres is no longer than $1 \mathrm{~s}$ [28]. For such a reason, a stable doubly charged ion can be lost in such environments through one of the following reactions: (i) chemical reaction with a neutral partner; (ii) recombination with a thermal electron; or (iii) Coulomb explosion $[6,13,28]$. On the other hand, molecular dications can be formed in a metastable state having a lifetime shorter than $1 \mathrm{~s}$, as discussed in the next section. In such a case, they can undergo many dissociation reactions towards fragment ions with a high kinetic energy content because they are unstable with respect to Coulomb explosion. Among these ions, some may experience collisions and may release their energy, but some of them may reach the top of the atmosphere and may escape into space, in particular, those metastable dications formed at around the exobase level (above this altitude, which is about $200 \mathrm{~km}$ on Mars with a ground pressure of $636 \mathrm{~Pa}$, the pressure force does not play any role because of rare collisions, and the particles have an escape probability equal to $1 / \mathrm{e}$ ) [28,35]. A very interesting and recent study by Lilensten et al. [35] investigated the role of $\mathrm{CO}_{2}{ }^{2+}$ molecular dications in the atmospheric escape of Mars, showing that, in general, dications may constitute a source of the escape of planetary atmospheres, which had not been taken into account until now. Actually, the escape probability of molecules depends on gravitational forces. However, sometimes a simple thermal distribution cannot explain the escape rate of some species. This indicates that some chemical processes must be responsible for high kinetic energy products, like charge exchange or photodissociation phenomena. Lilensten et al., retrieving the measured electron escape flux, were able to perform a first attempt in the evaluation of the escape flux of fast ions due to dissociation of the unstable $\mathrm{CO}_{2}{ }^{2+}$ dication. In the case of Mars atmosphere, with a mean solar flux $\mathrm{F}_{10.7}=120$ (for details, see the Appendix A in [35]), they obtained an escape flux of fast ions of about $8.4 \times 10^{23} \mathrm{~s}^{-1}$, indicating that, in general, this escape process should account for up to about $6 \%$ of the total, with the escape of thermal ions accounting for the remainder. However, their calculations extended to Venus and HD 209458 b (one of the three observed exoplanets, i.e., "hot Jupiters" gas giants) do not agree with experimental observations, and, in the latter case, cannot explain the measured escape flux of $\mathrm{C}^{+}$[35]. We consider that this should be an indication that the role of metastable molecular dications in the production of fast fragment ionic species able to escape into space is still underestimated in the kinetic modeling of planetary ionospheres. 
The aim of this paper is to stimulate the research in the field of chemical characterization of planetary atmospheres in order to focus the attention of the scientific community on the role of molecular dications inducing Coulomb explosion and fragment ion formation with a high kinetic energy content. For such a reason, molecular dications are considered as exotic species, and when they are formed in planetary ionospheres, the possibility of generating dissociative products with a kinetic energy of several $\mathrm{eV}$ allows these ionic fragments to reach sufficient velocity to escape into space. Therefore, double ionization processes can, in principle, contribute to the continuous erosion of the atmosphere of some planets of the Solar System, like Mars and Titan (the largest satellite of Saturn), as discussed in the following sections.

\section{Experiments}

The data presented and discussed here have been recorded by double photoionization experiments performed at the ELETTRA Synchrotron Light Laboratory (Trieste, Italy) using the ARPES (Angle-Resolved Photoemission Spectroscopy) end station of the Gas Phase Beamline. Details on the beamline and the end station have already been reported elsewhere [36], and the apparatus used for the experiment discussed here has also been described previously [37,38]. Therefore, only some features relevant to the present investigation are outlined here.

As observed in Figure 1, the monochromatic energy from the selected synchrotron light beam crosses an effusive molecular beam of $\mathrm{CO}_{2}, \mathrm{~N}_{2} \mathrm{O}$ and $\mathrm{C}_{2} \mathrm{H}_{2}$ neutral precursors, and the product ions are then detected in coincidence with photoelectrons.

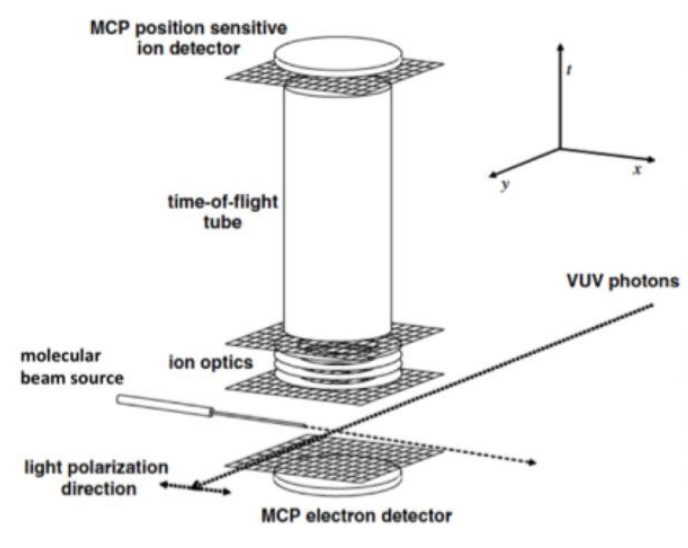

(a)

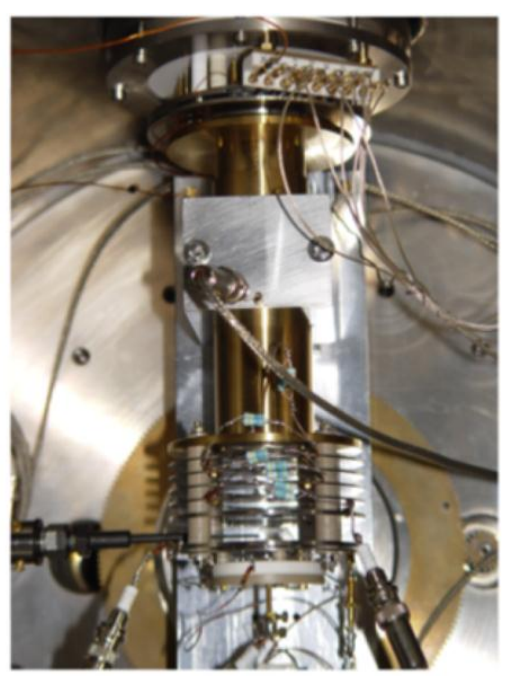

(b)

Figure 1. The electron-ion extraction and detection system used for the photoelectron-photoion coincidence measurements. (a) a scheme of the set-up and (b) a picture of such a device.

The molecular beam of $\mathrm{CO}_{2}, \mathrm{~N}_{2} \mathrm{O}$ and $\mathrm{C}_{2} \mathrm{H}_{2}$ crosses at right angles the VUV light beam, having the light polarization vector parallel to the synchrotron ring plane and perpendicular to the time-of-flight direction of detected ions. Incident photon fluxes and the gas pressure are monitored, and the ion yield has been corrected for flux changes of pressure and photons, when the photon energy was scanned. The gas inlet effusive source is supplied with a mixture of the molecule under study $\left(\mathrm{CO}_{2}\right.$, $\mathrm{N}_{2} \mathrm{O}$ and $\mathrm{C}_{2} \mathrm{H}_{2}$ ) with helium, allowing the normalization of all ion signals (measured at each photon energy) to the total ion yield of helium at that energy. In order to record photoions in coincidence with photoelectrons, we used the electron-ion-ion coincidence technique. The coincidence electron-ion-ion extraction and detection system was built following the model described in detail in [18] and its scheme can be seen in Figure 1. This device consists of a time-of-flight (TOF) spectrometer equipped 
with an ion position sensitive detector (stack of three micro-channel-plates with a multi-anode array arranged in 32 rows and 32 columns). It has been especially designed in order to properly measure the spatial momentum components of the dissociation ionic products [37]. Finally, by the analysis of distribution maps, the kinetic energy of the two products, released into the two ionic fragments, can be extracted. Such kinetic energy is obtained by a simple analysis of the ion intensity maps based on the method suggested by Lundqvist et al. [39,40]. In particular, this target can be reached by looking at the dimensions and shapes of the peak for each ion pair in the coincidence spectra measured at all investigated photon energies. Through analysis of coincidences distribution as a function of the arrival time differences $\left(t_{2}-t_{1}\right)$ of fragment ions (to the ion position sensitive detector, being a multi-channel-plate (MCP)) generated by Coulomb explosion of the molecular dication under study, we are able to calculate the lifetime of such metastable species by using the procedure proposed by Field and Eland [41-43]. All experimental components were controlled by a computer used to record experimental data. The incident photon flux and the gas pressure were monitored and stored in separate acquisition channels $[39,44]$.

Carbon dioxide, nitrous oxide and acetylene, from a commercial cylinder at room temperature, were supplied to a needle effusive beam source. The used $\mathrm{CO}_{2}, \mathrm{~N}_{2} \mathrm{O}$ and $\mathrm{C}_{2} \mathrm{H}_{2}$ gases had a $99.99 \%$ and $\sim 99.0 \%$ (in the case of acetylene) nominal purity. Carbon dioxide and nitrous oxide were used without any further treatment, whereas acetylene was used after a $193 \mathrm{~K}$ cold trap purging to remove acetone impurities. The performance of the cold trap was verified by recording mass spectra. An adjustable leak valve along the input gas pipe line was used in order to control the gas flow, which was monitored by checking the pressure in the main vacuum chamber.

\section{Results and Discussion}

Carbon dioxide, nitrous oxide and acetylene are simple molecules of interest for interstellar medium ISM and planetary atmospheres (not only for the Earth but also for other planets of the Solar System like Mars, Venus and also Titan). The presence of $\mathrm{CO}_{2}, \mathrm{~N}_{2} \mathrm{O}$ in the ISM has been demonstrated by microwave spectroscopy, whereas $\mathrm{C}_{2} \mathrm{H}_{2}$ was detected by IR spectroscopic measurements [33]. Acetylene is also found as a minor component in the atmosphere of gas giants like the planet Jupiter, in the atmosphere of Saturn's satellite Titan, and in comets, where photochemical experiments have demonstrated that this simple hydrocarbon is a likely precursor of $\mathrm{C}_{2}$, a widely observed component in such environments [45-48].

On the other hand, the importance of carbon dioxide and nitrous oxide are well known in the Earth's atmosphere where both species are important greenhouse gases and $\mathrm{N}_{2} \mathrm{O}$ can participate in ozone depletion [49,50]. Moreover, $\mathrm{CO}_{2}$ is the main component of the Mars $(95.3 \%)$ and Venus $(96.5 \%)$ atmospheres and, together with acetylene molecules, has been detected as a minor component in Titan's atmosphere (2-4 ppm and about $10 \mathrm{ppb}$, respectively) [51]. It has to be noted that the presence of VUV light photons in these environments makes it highly probable that double photoionization of these molecular species occurs with their subsequent dissociation into ionic fragments having a high kinetic energy content of several $\mathrm{eV}$. This translational energy is sufficient for some of them to escape from the upper atmosphere of Mars and Titan into space, as we discuss in the following subsections.

\subsection{The Double Photoionization of $\mathrm{CO}_{2}$ and the Lack of $\mathrm{O}^{+}$Concentration in Mars Atmosphere}

The double photoionization of $\mathrm{CO}_{2}$ by VUV synchrotron light (34-50 eV energy range) is in good agreement with previous data $[21,51-53]$ and indicates that four two-body dissociation processes are possible with their measured threshold energies:

$$
\begin{gathered}
\mathrm{CO}_{2}+\mathrm{h} v \rightarrow\left(\mathrm{CO}_{2}^{+}\right)^{*}+\mathrm{e}^{-} \rightarrow \mathrm{CO}^{+}+\mathrm{O}^{*} \rightarrow \mathrm{CO}^{+}+\mathrm{O}^{+}+\mathrm{e}^{-} \quad \mathrm{h} v \geq 35.6 \mathrm{eV} \\
\mathrm{CO}_{2}+\mathrm{h} v \rightarrow \mathrm{CO}_{2}{ }^{2+}+2 \mathrm{e}^{-} \quad \mathrm{h} v \geq 37.3 \mathrm{eV} \\
\mathrm{CO}_{2}+\mathrm{h} v \rightarrow\left(\mathrm{CO}_{2}{ }^{2+}\right)^{*} \text { long lived }+2 \mathrm{e}^{-} \rightarrow \mathrm{CO}^{+}+\mathrm{O}^{+} \quad \mathrm{h} v \geq 38.7 \mathrm{eV}
\end{gathered}
$$




$$
\mathrm{CO}_{2}+\mathrm{h} v \rightarrow\left(\mathrm{CO}_{2}{ }^{2+}\right)^{*} \text { short lived }+2 \mathrm{e}^{-} \rightarrow \mathrm{CO}^{+}+\mathrm{O}^{+} \quad \mathrm{h} v \geq 39.0 \mathrm{eV}
$$

In our mass spectrometric determinations, no clear evidence was found for possible three-body dissociation reactions despite that Eland and coworkers [22] were able to detect the final ion products generated from the three body dissociative double photoionization processes of some triatomic molecules $\left(\mathrm{SO}_{2}, \mathrm{CS}_{2}, \mathrm{OCS}, \mathrm{ICN}, \mathrm{CO}_{2}\right.$, and $\left.\mathrm{N}_{2} \mathrm{O}\right)$ at a photon energy higher than $40 \mathrm{eV}$. The reason for such a discrepancy is probably due to the low cross-section values characterizing the three body fragmentation channels in the energy range investigated in our experiment. In Reactions (3) and (4), several electronic states of the intermediate molecular $\left(\mathrm{CO}_{2}{ }^{2+}\right)$ dication are involved with different lifetimes $\tau$. Reaction (3) occurs through a long-lived dication with $\tau \geq 3.1 \mu$ s corresponding to the formation of $\mathrm{CO}_{2}{ }^{2+}$ ions in the ground $\mathrm{X}^{3} \Sigma^{+} \mathrm{g}$ electronic state with an internal energy below the threshold towards the Coulomb explosion or in excited singlet states undergoing slow spin forbidden intersystem crossing to the triplet ground state, followed by fast dissociation over the ground state potential energy surface [21,53]. Reaction (4) involves a short-lived dication having $\tau \leq 50 \mathrm{~ns}$ corresponding to the formation of the ground $\mathrm{X}^{3} \Sigma^{+} \mathrm{g}$ electronic state with an internal energy above the threshold for dissociation. Reactions (1), (3) and (4) form the same $\mathrm{CO}^{+}$and $\mathrm{O}^{+}$product ions. In particular, reaction (1) is an indirect process occurring below the double photoionization threshold of $37.34 \mathrm{eV}$, via the formation of an excited state of the $\left(\mathrm{CO}_{2}{ }^{+}\right)^{*}$ monocation, followed by the production of an intermediate autoionizing oxygen atom $\mathrm{O}^{*}$.

By analysing coincidence spectra obtained for each investigated photon energy, we can evaluate the kinetic energy release (KER) for the $\mathrm{CO}^{+}$and $\mathrm{O}^{+}$production in the "fast" fragmentation process by looking at the dimensions and shapes of the dot intensity for each ion pair peak. With such a procedure, applied to the $\mathrm{CO}^{+} / \mathrm{O}^{+}$coincidences signal related to the Reactions (1) and (4) fragmentation processes, we have measured kinetic energy distributions of each product ions for different values of the investigated photon energy (36.0, 39.0, 41.0, 44.0 and $49.0 \mathrm{eV})$ as shown in Figure 2.

From the kinetic energy distributions reported in Figure 2, it is evident that the maximum KER value for the $\mathrm{O}^{+}$ions ranges between 2.2 and $3.8 \mathrm{eV}$ at all investigated photon energies. This is a consequence of the general behavior of doubly charged molecular ions coming from their instability towards the Coulomb explosion, with the subsequent formation of dissociative ionic fragments with a kinetic energy of several $\mathrm{eV}$, as already mentioned above. In the case of $\mathrm{O}^{+}$formation by VUV double photoionization of carbon dioxide molecules, this energy is large enough for the atmosphere of Mars and Titan to allow these fragments to reach enough velocity to escape into space, contributing to the continuous erosion of these atmospheres. In Table 1 are reported the measured KER values for fragments ions produced by VUV dissociative double photoionization of $\mathrm{CO}_{2}, \mathrm{C}_{2} \mathrm{H}_{2}$ and $\mathrm{N}_{2} \mathrm{O}$ in comparison with the typical escape energy for various ions at the exobase in the atmosphere of Earth, Venus, Mars and Titan [28]. In particular, considering the ionosphere of Mars, the possibility to form carbon dioxide $\mathrm{CO}_{2}{ }^{2+}$ dications (due to $\mathrm{UV}$ light double photoionization of $\mathrm{CO}_{2}$ neutral precursors) in this environment followed by its Coulomb explosion and subsequent production of $\mathrm{O}^{+}$fragments having a high translational energy (ranging between 2.2 and $3.8 \mathrm{eV}-$ see Figure 2), could explain the lack in the $\mathrm{O}^{+}$expected concentration in Mars' atmosphere. In fact, by looking at $\mathrm{O}^{+}$, we can argue that the observed behavior of its density profile measured by Viking 1 lander in the upper atmosphere of Mars, compared with the $\mathrm{CO}_{2}{ }^{2+}$ density profile as calculated by Witasse et al. for Viking 1 lander and Mariner 6 spacecraft geophysical conditions (see Figure 2) [33], could be explained by invoking the dissociative double photoionization of $\mathrm{CO}_{2}$ induced by VUV photons. These authors found a maximum in the $\mathrm{CO}_{2}{ }^{2+}$ density of about $5 \times 10^{6}$ ions $\cdot \mathrm{m}^{-3}$ at an altitude of $160 \mathrm{~km}$ where the $\mathrm{O}^{+}$ concentration (measured by Viking 1 with an ion density decreasing from $6 \times 10^{8}$ ions $\cdot \mathrm{m}^{-3}$ at $250 \mathrm{~km}$ to $1 \times 10^{8}$ ions $\cdot \mathrm{m}^{-3}$ at $175 \mathrm{~km}$ of altitude) disappears, becoming undetectable [33]. This surprising behaviour could be explained by our experimental observations discussed here: by double VUV photoionization of $\mathrm{CO}_{2}$ molecules, when the photon energy is higher than $48 \mathrm{eV}$, the stable molecular dication formation (Reaction (2)) and the "fast" fragmentation process (Reactions (1) and (4)) achieve the same importance and their cross sections gain the maximum value, so the $\mathrm{O}^{+}$formation with a KER 
sufficient to escape from the atmosphere of Mars becomes very high and its experimental detectability very difficult. An analogous situation could characterize Titan's ionosphere, where the low typical escape energy values for ions (see Table 1) allow for the high probability of the escape process into space, not only for $\mathrm{O}^{+}$, but also for $\mathrm{CO}^{+}$ions, having typical escape energy smaller than $1.0 \mathrm{eV}$.
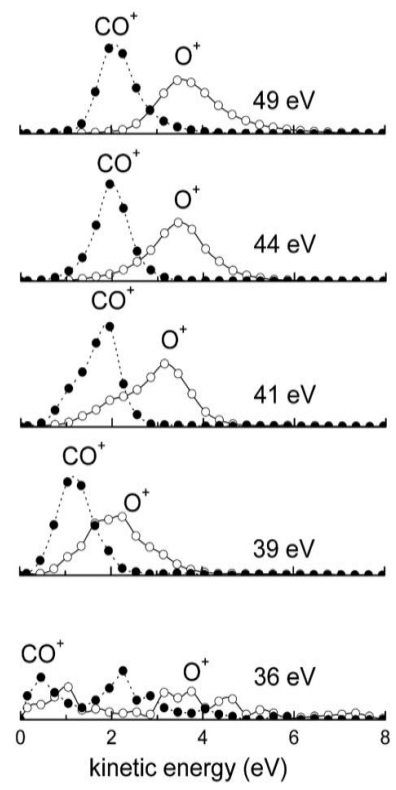

(a)

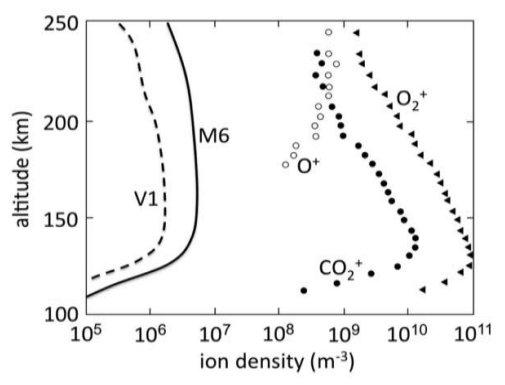

(b)

Figure 2. (a) Kinetic energy distributions for $\mathrm{CO}^{+}$and $\mathrm{O}^{+}$fragment ions originating by Coulomb explosion of $\mathrm{CO}_{2}{ }^{2+}$ dication produced in the double VUV photoionization experiment of $\mathrm{CO}_{2}$, as a function of the photon energy. (b) Calculation of $\mathrm{CO}_{2}{ }^{2+}$ ion density profiles for Viking 1 lander (V1) and Mariner 6 spacecraft (M6) conditions by Witasse et al. [33]. The $\mathrm{O}^{+}, \mathrm{CO}_{2}{ }^{+}$, and $\mathrm{O}_{2}{ }^{+}$densities profiles (on the right part of the panel) measured by Viking 1 lander are also plotted.

Table 1. The range of measured values of KER distributions $(\mathrm{eV})$ for fragments ions produced by VUV dissociative double photoionization of $\mathrm{CO}_{2}, \mathrm{~N}_{2} \mathrm{O}, \mathrm{C}_{2} \mathrm{H}_{2}$ in the range of 28-65 eV compared with the typical escape energy $(\mathrm{eV})$ for various ions in the atmosphere of Earth, Venus, Mars and Titan [28].

\begin{tabular}{cccccc}
\hline \multirow{2}{*}{$\begin{array}{c}\text { Ionic } \\
\text { Species }\end{array}$} & $\begin{array}{c}\text { Measured Range of } \\
\text { KER Distributions (eV) }\end{array}$ & \multicolumn{3}{c}{$\begin{array}{c}\text { Typical Escape Energy (eV) for Various Ions in the Atmosphere } \\
\text { (at the Exobase) of Some Planets of the Solar System [28] }\end{array}$} \\
\cline { 3 - 6 } & & Earth & Venus & Mars & Titan \\
\hline $\mathrm{H}^{+}$ & $2.8 \div 6.0^{(\mathrm{a})}$ & 0.62 & 0.53 & 0.13 & 0.02 \\
$\mathrm{C}^{+}$ & $1.7 \div 3.3^{\text {(b) }}$ & 7.4 & 6.4 & 1.5 & 0.28 \\
$\mathrm{CH}^{+}$ & $1.3 \div 3.2^{(\mathrm{c})}$ & 8.0 & 6.9 & 1.6 & 0.30 \\
$\mathrm{CH}_{2}{ }^{+}$ & $1.6 \div 2.9^{(\mathrm{b})}$ & 8.6 & 7.5 & 1.8 & 0.32 \\
$\mathrm{~N}^{+}$ & $2.3 \div 5.2^{(\mathrm{d})}$ & 8.6 & 7.5 & 1.8 & 0.32 \\
$\mathrm{O}^{+}$ & $1.0 \div 5.2^{(\mathrm{e})}$ & 9.8 & 8.6 & 2.0 & 0.37 \\
$\mathrm{C}_{2} \mathrm{H}^{+}$ & $2.2 \div 3.8^{(\mathrm{f})}$ & & 13.3 & 3.1 & 0.58 \\
$\mathrm{CO}^{+}$ & $0.1 \div 0.4^{(\mathrm{a})}$ & 15.4 & 14.9 & 3.5 & 0.65 \\
$\mathrm{~N}_{2}^{+}$ & $0.4 \div 2.6^{(\mathrm{f})}$ & 17.3 & 14.9 & 3.5 & 0.65 \\
$\mathrm{NO}^{+}$ & $0.4 \div 2.9^{(\mathrm{e})}$ & 17.3 & 16.0 & 3.75 & 0.70 \\
\hline
\end{tabular}

(a) formed by Reactions (8) + (9)—see text; (b) formed by Reaction (11)—see text; (c) formed by Reaction (10)—see text; ${ }^{\text {(d) }}$ formed by Reaction (6)—see text; ${ }^{\text {(e) }}$ formed by Reaction (5)—see text; ${ }^{(f)}$ formed by Reactions (1) + (4)—see text.

\subsection{The Coulomb Explosion of Nitrous Oxide Dication}

When nitrous oxide molecules are photoionized by using VUV synchrotron radiation in the $28-40 \mathrm{eV}$ energy range, the production of $\mathrm{N}_{2} \mathrm{O}^{2+}$ molecular dications in a metastable state is possible. 
After its formation, $\mathrm{N}_{2} \mathrm{O}^{2+}$ can evolve towards the formation of $\mathrm{N}_{2}{ }^{+} / \mathrm{O}^{+}$and $\mathrm{N}^{+} / \mathrm{NO}^{+}$ionic fragments via Coulomb explosion (see Reactions (5) and (6) reported below, respectively). According to a previous study [49], to which we refer for an overview of the experimental and theoretical works already performed by several research groups, no stable $\mathrm{N}_{2} \mathrm{O}^{2+}$ molecular dications have been observed in our experiment, indicating that the lifetime of the produced molecular dications is never longer than $10^{-6} \mathrm{~s}$, which was the typical average time-of-flight of the ions in our detection device. In the whole investigated energy range, we observed the two dissociation channels reported below with a threshold energy of about $32.2 \mathrm{eV}$ :

$$
\begin{aligned}
& \mathrm{N}_{2} \mathrm{O}+\mathrm{h} v \rightarrow\left(\mathrm{N}_{2} \mathrm{O}^{2+}\right)^{*}+2 \mathrm{e}^{-} \rightarrow \mathrm{N}_{2}^{+}+\mathrm{O}^{+}+2 \mathrm{e}^{-} \\
& \mathrm{N}_{2} \mathrm{O}+\mathrm{h} v \rightarrow\left(\mathrm{N}_{2} \mathrm{O}^{2+}\right)^{*}+2 \mathrm{e}^{-} \rightarrow \mathrm{N}^{+}+\mathrm{NO}^{+}+2 \mathrm{e}^{-}
\end{aligned}
$$

No evidence for three-body dissociation reactions was found in our investigated photon energy range, in agreement with previous results by Eland and coworkers, who found product ions originating from the three-body fragmentation processes of the $\mathrm{N}_{2} \mathrm{O}^{2+}$ dication at a photon energy higher than $40 \mathrm{eV}$ [22]. In Reactions (5) and (6), $\left(\mathrm{N}_{2} \mathrm{O}^{2+}\right)^{*}$ indicates an intermediate "short-lived" molecular dication. In such an experiment, product ions were detected as a function of the photon energy, in coincidence with one of the two photoelectrons and the recorded delay times. Recorded correlation time diagrams have shown that, for energies below the vertical threshold for the $\mathrm{N}_{2} \mathrm{O}^{2+}$ dication formation $(35.8 \mathrm{eV})$, autoionizing states are formed, followed by dissociative autoionization finally leading to ion products of both Reactions (5) and (6). By increasing the photon energy, $\mathrm{N}_{2} \mathrm{O}^{2+}$ can be formed above the threshold, and also in this case, it dissociates through the same channels by a direct Coulomb explosion [49]. Now, we are able to analyze our data using the same procedure already discussed for $\mathrm{CO}_{2}$, providing the total kinetic energy of ionic fragments as a function of the investigated photon energy. In Figure 3 are reported the maximum values of the peak for the total kinetic energy of the two couples of product ions $\mathrm{N}^{+}+\mathrm{NO}^{+}$and $\mathrm{O}^{+}+\mathrm{N}_{2}{ }^{+}$originating from Reactions (5) and (6), respectively, as a function of the photon energy.

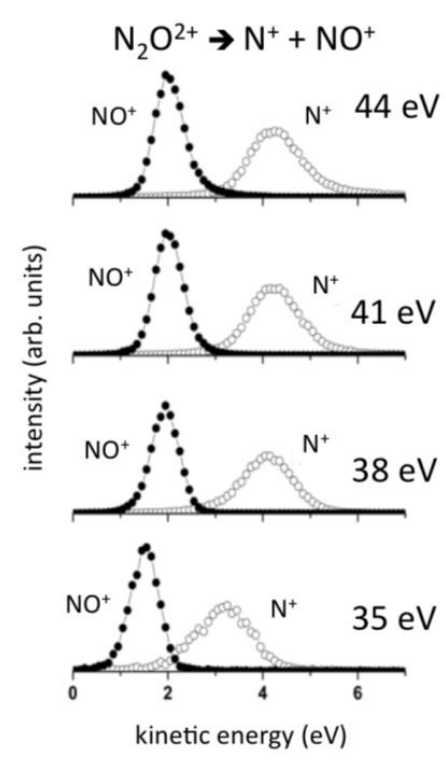

(a)

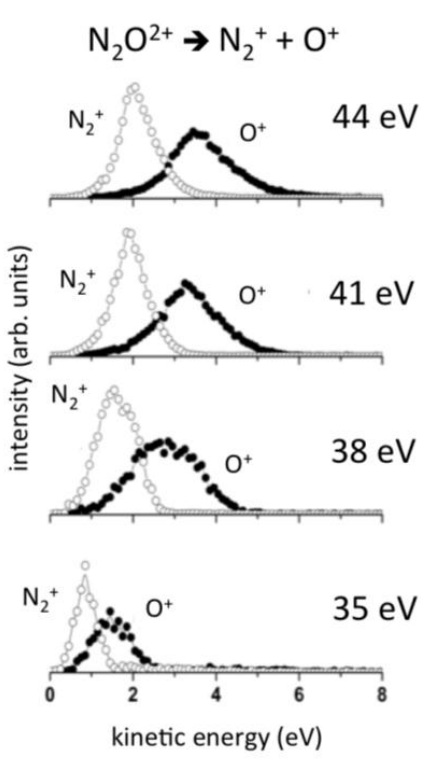

(b)

Figure 3. (a) Kinetic energy distributions for each fragment ion $\mathrm{N}^{+}$and $\mathrm{NO}^{+}$(see Reaction (6) on the text) originating from the Coulomb explosion of $\mathrm{N}_{2} \mathrm{O}^{2+}$ dication, produced in the double VUV photoionization experiment of nitrous oxide (see text), as a function of the investigated photon energy. (b) measured kinetic energy distributions for $\mathrm{N}_{2}{ }^{+}$and $\mathrm{O}^{+}$ions (see Reaction (5) on the text) originating from the Coulomb explosion of $\mathrm{N}_{2} \mathrm{O}^{2+}$, and produced in the same experiment discussed in the text. 
From Figure 3, it is possible to see that ions produced by Reaction (5), $\mathrm{O}^{+}+\mathrm{N}_{2}{ }^{+}$, are formed with a total KER of about $5.0 \mathrm{eV}$, while $\mathrm{N}^{+}+\mathrm{NO}^{+}$originating from Reaction (6) posses a total KER of about $6.0 \mathrm{eV}$. Looking at the typical escape energy for various ions reported in Table 1, we can argue that the measured kinetic energy content (ranging between 1.0 and $2.3-5.2 \mathrm{eV}$, respectively) for both $\mathrm{O}^{+}$and $\mathrm{N}^{+}$, produced by dissociative double VUV photoionization of nitrous oxide is, in principle, compatible with their possible escape from the upper atmosphere of Mars and Titan

\subsection{The Coulomb Explosion of Acetylene Dication}

The double photoionization of acethylene by using VUV synchrotron radiation in the 32-65 eV photon energy range produces acetylene dication with subsequent dissociation reactions. Our previous measurements [44], in agreement with experimental determinations by Eland and coworkers [22], show the following accessible channels with their respective threshold energies:

$$
\begin{gathered}
\mathrm{C}_{2} \mathrm{H}_{2}+\mathrm{h} v \rightarrow \mathrm{C}_{2} \mathrm{H}_{2}{ }^{2+}+2 \mathrm{e}^{-} \quad \mathrm{h} v \geq 31.7 \mathrm{eV} \\
\mathrm{C}_{2} \mathrm{H}_{2}+\mathrm{h} v \rightarrow\left(\mathrm{C}_{2} \mathrm{H}_{2}{ }^{2+}\right)^{*} \text { long lived }+2 \mathrm{e}^{-} \rightarrow \mathrm{H}^{+}+\mathrm{C}_{2} \mathrm{H}^{+} \quad \mathrm{h} v \geq 33.8 \mathrm{eV} \\
\mathrm{C}_{2} \mathrm{H}_{2}+\mathrm{h} v \rightarrow\left(\mathrm{C}_{2} \mathrm{H}_{2}{ }^{2+}\right)^{*}+2 \mathrm{e}^{-} \rightarrow \mathrm{H}^{+}+\mathrm{C}_{2} \mathrm{H}^{+} \quad \mathrm{h} v \geq 34.0 \mathrm{eV} \\
\mathrm{C}_{2} \mathrm{H}_{2}+\mathrm{h} v \rightarrow\left(\mathrm{C}_{2} \mathrm{H}_{2}{ }^{2+}\right)^{*}+2 \mathrm{e}^{-} \rightarrow \mathrm{CH}^{+}+\mathrm{CH}^{+} \quad \mathrm{h} v \geq 34.0 \mathrm{eV} \\
\mathrm{C}_{2} \mathrm{H}_{2}+\mathrm{h} v \rightarrow\left(\mathrm{C}_{2} \mathrm{H}_{2}{ }^{2+}\right)^{*}+2 \mathrm{e}^{-} \rightarrow\left(\mathrm{H}_{2} \mathrm{CC}^{2+}\right)^{*} \rightarrow \mathrm{C}^{+}+\mathrm{CH}_{2}{ }^{+} \quad \mathrm{h} v \geq 34.0 \mathrm{eV}
\end{gathered}
$$

where $\mathrm{C}_{2} \mathrm{H}_{2}{ }^{2+}$ indicates a stable molecular dication formation, $\left(\mathrm{C}_{2} \mathrm{H}_{2}{ }^{2+}\right)^{*}$ long-lived refers to a molecular dication with a lifetime of $108 \pm 22 \mathrm{~ns}$, as we determined in our recent work [44], and $\left(\mathrm{C}_{2} \mathrm{H}_{2}{ }^{2+}\right)^{*}$ indicates a doubly charged intermediate molecular species with a lifetime shorter than the characteristic window time of our apparatus for the probed experimental conditions, that is $\sim 50 \mathrm{~ns}$. Reactions (8) and (9) indicate two different mechanisms for the same deprotonation process, involving intermediate "long-lived" and "short-lived" dication species, respectively. Reaction (11) is a proton transfer rearrangement reaction which occurs via formation of the intermediate vinylidene dication, $\left(\mathrm{H}_{2} \mathrm{CC}^{2+}\right)^{*}$, with subsequent dissociation towards the $\mathrm{C}^{+}$and $\mathrm{C}_{2} \mathrm{H}^{+}$ion products $[22,44]$.

In the present experiment, we have focused our attention on the two-body dissociation Reactions (8)-(11) originating from Coulomb explosion of $\mathrm{C}_{2} \mathrm{H}_{2}{ }^{2+}$ dications, induced by $39.0 \mathrm{eV}$ photons, and using photoelectron-photoion-photoion coincidence and ion imaging techniques. The recorded coincidence plot at this energy is reported in Figure 4a. By analyzing the density distribution of the recorded coincidences, we are able to extract a lifetime of $108 \pm 22 \mathrm{~ns}$ for the intermediate "long-lived" $\mathrm{C}_{2} \mathrm{H}_{2}{ }^{2+}$ molecular dication of Reaction (8), and the kinetic energy distributions of each product ion (see Figure $4 \mathrm{~b}$ ) by using the same procedure already discussed in the case of carbon dioxide.

In the Figure 4a are also shown the total kinetic energy distributions related to product ion pairs of Reactions (8)-(11). Such total KER distributions show: (i) for the deprotonation process (Reactions (8) and (9)), a maximum at about $4.3 \mathrm{eV}$ with a full width at half maximum (FWHM) of about $60 \%$; (ii) for the symmetric dissociation (Reaction (10)) a maximum at $5.2 \mathrm{eV}$ with a FWHM of $44 \%$; and (iii) for the proton transfer rearrangement process via formation of the intermediate vinylidene dication (Reaction (11)) a maximum in the KER distribution at $4.5 \mathrm{eV}$ with a FWHM of about $28 \%$. One interesting characteristic of such distributions is that the one referred to the deprotonation process leading to the formation of $\mathrm{H}^{+}$and $\mathrm{C}_{2} \mathrm{H}^{+}$ions shows bimodal behavior (see Figure 4a) originated by the two possible mechanisms contributing to this reaction: (i) a "slow" dissociation component, Reaction (8), more important at low photon energy ( $\mathrm{hv} \leq 35 \mathrm{eV}$ ) where $\mathrm{C}_{2} \mathrm{H}_{2}{ }^{2+}$ is formed mainly in its ground ${ }^{3} \Sigma^{-}$g electronic state with a measured lifetime of about $108 \mathrm{~ns}$; and (ii) a "fast" dissociation component, Reaction (9), via formation of a "short-lived" $\mathrm{C}_{2} \mathrm{H}_{2}{ }^{2+}$ intermediate dication having a lifetime shorter than $50 \mathrm{~ns}$ and coming from the ${ }^{3} \Pi_{\mathrm{u}}$ excited electronic state whose accessible Franck-Condon zone occurs at about $37 \mathrm{eV}$. This state, accordingly to the potential energy curves 
calculated by Thyssen et al. [22], correlates to ground state $\mathrm{C}_{2} \mathrm{H}^{+}$and $\mathrm{H}^{+}$products along an entirely repulsive curve with an energy release of about 7-8 eV. This "fast" component for the deprotonation reaction is expected to play an important role as the photon energy becomes higher than $36.0 \mathrm{eV}$ and should be characterized by a higher KER for the product $\mathrm{C}_{2} \mathrm{H}^{+}$and $\mathrm{H}^{+}$ions with respect to the "slow" component which involves the formation of the ${ }^{3} \Sigma^{-}$g dicationic metastable state. The presence of two different mechanisms for this process is confirmed by the quite broad FWHM value $(\sim 60 \%)$ of the related total KER distribution (see Figure $4 \mathrm{~b})$. In order to clarify the relative importance of the two mechanisms discussed above (see Reactions (8) and (9)), we are planning to extend our photoelectron-photoion-photoion coincidence and ion imaging study to a wider photon energy range. Finally, it has to be noted that the translational energy content of each $\mathrm{H}^{+}, \mathrm{C}^{+}, \mathrm{CH}^{+}$and $\mathrm{CH}_{2}{ }^{+}$product ion is quite large, with an average value of 4.0, 2.5, 2.0 and $2.5 \mathrm{eV}$, respectively. This kinetic energy is sufficient to allow this species to participate in atmospheric escape from Mars and Titan (see Figure 4 and Table 1).

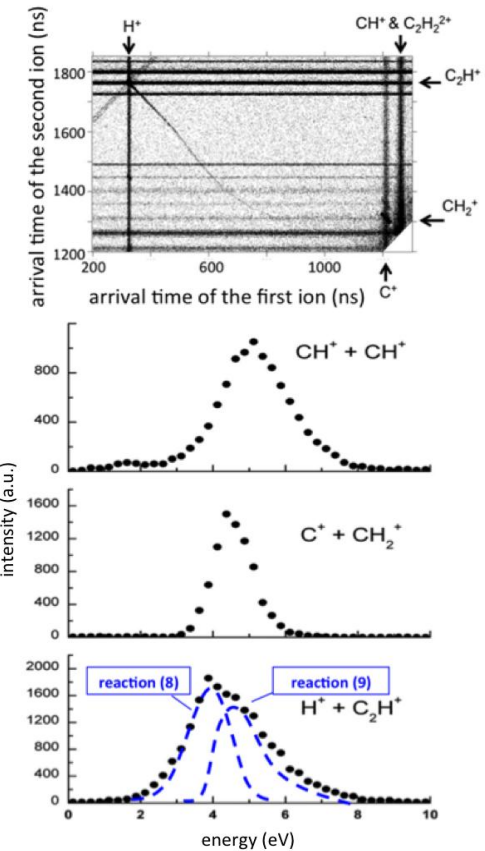

(a)

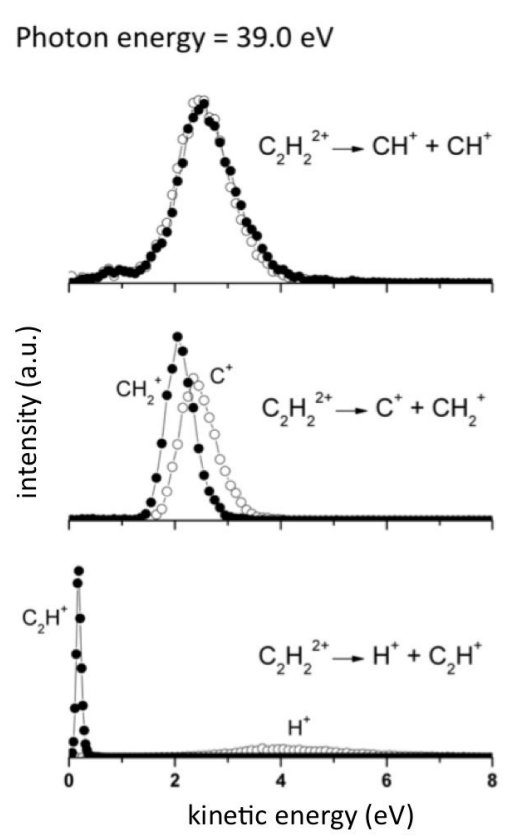

(b)

Figure 4. (a) on the top is the photoion-photoion coincidence plot as measured at a photon energy of $39 \mathrm{eV}$; on the bottom are the total kinetic energy distributions of product ions for the three measured two-body dissociation reactions indicating in the case of $\mathrm{H}^{+}+\mathrm{C}_{2} \mathrm{H}^{+}$ions, formation of a bimodal distribution due to the presence of different reaction mechanisms (see text). (b) Kinetic energy distributions for each two-body fragment ion originating from the Coulomb explosion of the $\mathrm{C}_{2} \mathrm{H}_{2}{ }^{2+}$ molecular dication (see Reactions (7)-(11) and text), as measured at a photon energy of $39 \mathrm{eV}$.

\section{Conclusions}

The dissociative double photoionization processes, induced by VUV light photons and producing fragment ions with a high kinetic energy content, could be a generally important way for ionic species to escape from the atmosphere of some planets of the Solar System, like Venus, Mars and Titan. In fact, these processes occur via formation of intermediate molecular dications that could dissociate by Coulomb explosion towards the formation of two ionic fragment species having a kinetic energy release of several $\mathrm{eV}$, and therefore, much larger than the limiting thermal escape velocity characterizing some planetary atmospheres. In the case of the double VUV photoionization of $\mathrm{CO}_{2}$, $\mathrm{C}_{2} \mathrm{H}_{2}$ and $\mathrm{N}_{2} \mathrm{O}$ molecules (in the photon energy range of $28-65 \mathrm{eV}$ ), the fragment product ions $\mathrm{O}^{+}$, $\mathrm{CO}^{+}, \mathrm{N}^{+}, \mathrm{CH}_{2}{ }^{+}, \mathrm{CH}^{+}, \mathrm{C}^{+}, \mathrm{H}^{+}$are characterized by a translational energy ranging between 1.0 and 
$6.0 \mathrm{eV}$ that is large enough to allow their escape process from the upper atmospheres of Mars and Titan. Moreover, these studies could be helpful in understanding important details about the chemistry of planetary ionospheres, like in the case of Mars, where we were able to explain the observed behavior of the $\mathrm{O}^{+}$and $\mathrm{CO}_{2}{ }^{2+}$ ion density profiles.

Acknowledgments: Financial contributions from MIUR (Ministero dell'Istruzione, dell'Università e della Ricerca) through the PRIN 2009 (Grant 2009W2W4YF_002) project is gratefully acknowledged. The authors also gratefully thank the "Fondazione Cassa di Risparmio di Perugia" for partial support (Project code: 2014.0255.021).

Author Contributions: Stefano Falcinelli and Stefano Stranges conceived and designed the experiments; all authors performed the experiments; Stefano Falcinelli, Fernando Pirani, Michele Alagia and Franco Vecchiocattivi analyzed the data; Stefano Falcinelli, Michele Alagia, Luca Schio, Robert Richter and Stefano Stranges contributed reagents/materials/analysis tools; Stefano Falcinelli wrote the paper.

Conflicts of Interest: The authors declare no conflict of interest.

\section{Abbreviations}

The following abbreviations are used in this manuscript:

KER Kinetic Energy Released

VUV Vacuum Ultraviolet

UV Ultraviolet

ARPES Angle-Resolved Photoemission Spectroscopy

\section{References}

1. Balucani, N.; Bartocci, A.; Brunetti, B.G.; Candori, P.; Falcinelli, S.; Pirani, F.; Palazzetti, F.; Vecchiocattivi, F. Collisional autoionization dynamics of $\mathrm{Ne}^{*}\left({ }^{3} \mathrm{P}_{2,0}\right)-\mathrm{H}_{2} \mathrm{O}$. Chem. Phys. Lett. 2012, 546, 34-39. [CrossRef]

2. Brunetti, B.G.; Candori, P.; Cappelletti, D.; Falcinelli, S.; Pirani, F.; Stranges, D.; Vecchiocattivi, F. Penning Ionization Electron Spectroscopy of water molecules by metastable neon atoms. Chem. Phys. Lett. 2012. [CrossRef]

3. Falcinelli, S.; Bartocci, A.; Cavalli, S.; Pirani, F.; Vecchiocattivi, F. The stereo-dynamics of collisional autoionization of ammonia by helium and neon metastable excited atoms through molecular beam experiments. J. Chem. Phys. 2015. [CrossRef] [PubMed]

4. Falcinelli, S.; Bartocci, A.; Cavalli, S.; Pirani, F.; Vecchiocattivi, F. Stereo-dynamics in collisional autoionization of water, ammonia, and hydrogen sulfide with metastable rare gas atoms: Competition between intermolecular halogen and hydrogen bonds. Chem. Eur. J. 2016, 22, 764-771. [CrossRef] [PubMed]

5. Falcinelli, S.; Pirani, F.; Vecchiocattivi, F. The possible role of penning ionization processes in planetary atmospheres. Atmosphere 2015. [CrossRef]

6. Alagia, M.; Balucani, N.; Candori, P.; Falcinelli, S.; Pirani, F.; Richter, R.; Rosi, M.; Stranges, S.; Vecchiocattivi, F. Production of ions at high energy and its role in extraterrestrial environments. Rend. Lincei Sci. Fis. Nat. 2013. [CrossRef]

7. Vuitton, V.; Dutuit, O.; Smith, M.A.; Balucani, N. Chemistry of Titan's atmosphere. In Titan: Surface, Atmosphere and Magnetosphere; Wodarg, M., Müller-Wodarg, I., Griffith, C.A., Lellouch, E., Cravens, T.E., Eds.; Cambridge University Press: Cambridge, UK, 2003; pp. 224-284.

8. Falcinelli, S.; Rosi, M.; Candori, P.; Vecchiocattivi, F.; Farrar, J.M.; Pirani, F.; Balucani, N.; Alagia, M.; Richter, R.; Stranges, S. The escape probability of some ions from Mars and Titan ionospheres. In ICCSA 2014, Part I, Lecture Notes in Computer Science LNCS; Springer: Berlin/Heidelberg, Germany, 2014; Volume 8579, pp. 554-570.

9. Larsson, M.; Geppert, W.D.; Nyman, G. Ion chemistry in space. Rep. Prog. Phys. 2012, 75, 066901. [CrossRef] [PubMed]

10. Lombardi, A.; Faginas Lago, N.; Laganà, A.; Pirani, F.; Falcinelli, S. A bond-bond portable approach to intermolecular interactions: Simulations for N-methylacetamide and carbon dioxide dimers. In ICCSA 2012, Part I, Lecture Notes in Computer Science LNCS; Springer: Berlin/Heidelberg, Germany, 2012; pp. 387-400.

11. Pei, L.; Carrascosa, E.; Yang, N.; Falcinelli, S.; Farrar, J.M. Velocity map imaging study of charge-transfer and proton-transfer reactions of $\mathrm{CH}_{3}$ radicals with $\mathrm{H}_{3}{ }^{+}$. J. Phys. Chem. Lett. 2015, 6, 1684-1689. [CrossRef] [PubMed] 
12. Candori, P.; Falcinelli, S.; Pirani, F.; Tarantelli, F.; Vecchiocattivi, F. Interaction components in the hydrogen halide dications. Chem. Phys. Lett. 2007. [CrossRef]

13. Sabzyan, H.; Keshavarz, E.; Noorisafa, Z. Diatomic dications and anions. J. Iran. Chem. Soc. 2014, 11, 871. [CrossRef]

14. Falcinelli, S.; Fernandez-Alonso, F.; Kalogerakis, K.; Zare, R.N. Mass spectrometric detection of alkaline earth monohalide dications. Mol. Phys. 1996, 88, 663-672. [CrossRef]

15. Tosi, P.; Correale, R.; Lu, W.; Falcinelli, S.; Bassi, D. Production of the molecular dication $\mathrm{ArN}^{2+}$ in the reaction $\mathrm{Ar}^{2+}+\mathrm{N}_{2}$. Phys. Rev. Lett. 1999, 82, 450-452. [CrossRef]

16. Teixidor, M.M.; Pirani, F.; Candori, P.; Falcinelli, S.; Vecchiocattivi, F. Predicted structure and energetics of $\mathrm{HCl}^{2+}$. Chem. Phys. Lett. 2003, 379, 139-146. [CrossRef]

17. Alagia, M.; Brunetti, B.G.; Candori, P.; Falcinelli, S.; Teixidor, M.M.; Pirani, F.; Richter, R.; Stranges, S.; Vecchiocattivi, F. Threshold-photoelectron-spectroscopy-coincidence study of the double photoionization of HBr. J. Chem. Phys. 2004, 120, 6985-6991. [CrossRef] [PubMed]

18. Alagia, M.; Biondini, F.; Brunetti, B.G.; Candori, P.; Falcinelli, S.; Moix, T.M.; Pirani, F.; Richter, R.; Stranges, S.; Vecchiocattivi, F. The double photoionization of $\mathrm{HCl}$ : An ion-electron coincidence study. J. Chem. Phys. 2004, 121, 10508-10512. [CrossRef] [PubMed]

19. Alagia, M.; Candori, P.; Falcinelli, S.; Pirani, F.; Mundim, M.S.P.; Richter, R.; Rosi, M.; Stranges, S.; Vecchiocattivi, F. Dissociative double photoionization of benzene molecules in the 26-33 eV energy range. Phys. Chem. Chem. Phys. 2011, 13, 8245-8250. [CrossRef] [PubMed]

20. Price, S.D.; Eland, J.H.D.; Fournier, P.G.; Fournier, J.; Millié, P. Electronic states and decay mechanisms of the $\mathrm{N}_{2} \mathrm{O}^{2+}$ dication. J. Chem. Phys. 1988, 88, 1511-1515. [CrossRef]

21. Slattery, A.E.; Field, T.A.; Ahmad, M.; Hall, R.I.; Lambourne, J.; Penent, F.; Lablanquie, P.; Eland, J.H. Spectroscopy and metastability of $\mathrm{CO}_{2}{ }^{2+}$ molecular ions. J. Chem. Phys. 2005. [CrossRef] [PubMed]

22. Thissen, R.; Delwiche, J.; Robbe, J.M.; Duflot, D.; Flament, J.P.; Eland, J.H.D. Dissociations of the ethyne dication $\mathrm{C}_{2} \mathrm{H}_{2}{ }^{2+}$. J. Chem. Phys. 1993, 99, 6590-6599. [CrossRef]

23. Hochlaf, M.; Bennett, F.R.; Chambaud, G.; Rosmus, P. Theoretical study of the electronic states of $\mathrm{CO}_{2}{ }^{2+}$. J. Phys. B At. Mol. Opt. Phys. 1998, 31, 2163-2175. [CrossRef]

24. Sharma, V.; Bapat, B.; Mondal, J.; Hochlaf, M.; Giri, K.; Sathyamurthy, N. Dissociative double ionization of $\mathrm{CO}_{2}$ : Dynamics, energy levels, and lifetime. J. Phys. Chem. A 2007, 111, 10205-10211. [CrossRef] [PubMed]

25. Pauling, L. The normal state of the helium molecule-ions $\mathrm{He}_{2}{ }^{+}$and $\mathrm{He}_{2}^{++}$. J. Chem. Phys. 1933, 1, 56-59. [CrossRef]

26. Nicolaides, C.A. Energy generation from volcanic ground-states-Application to cold $\mathrm{He}_{2}{ }^{2+}$. Chem. Phys. Lett. 1989, 161, 547-553. [CrossRef]

27. Stauber, P.; Doty, S.D.; van Dishoeck, E.F.; Benz, A.O. X-ray chemistry in the envelopes around young stellar objects. Astron. Astrophys. 2005, 440, 949-966. [CrossRef]

28. Thissen, R.; Witasse, O.; Dutuit, O.; Wedlund, C.S.; Gronoff, G.; Lilensten, J. Doubly-charged ions in the planetary ionospheres: A review. Phys. Chem. Chem. Phys. 2011, 13, 18264-18287. [CrossRef] [PubMed]

29. Schio, L.; Li, C.; Monti, S.; Salén, P.; Yatsyna, V.; Feifel, R.; Alagia, M.; Richter, R.; Falcinelli, S.; Stranges, S.; Zhaunerchyk, V. NEXAFS and XPS studies of nitrosyl chloride. Phys. Chem. Chem. Phys. 2015, 17, 9040-9048. [CrossRef] [PubMed]

30. Alagia, M.; Bodo, E.; Decleva, P.; Falcinelli, S.; Ponzi, A.; Richter, R.; Stranges, S. The soft X-ray absorption spectrum of the allyl free radical. Phys. Chem. Chem. Phys. 2013, 15, 1310-1318. [CrossRef] [PubMed]

31. Falcinelli, S.; Rosi, M.; Candori, P.; Vecchiocattivi, F.; Farrar, J.M.; Pirani, F.; Balucani, N.; Alagia, M.; Richter, R.; Stranges, S. Kinetic energy release in molecular dications fragmentation after VUV and EUV ionization and escape from planetary atmospheres. Plan. Space Sci. 2014, 99, 149-157. [CrossRef]

32. Lilensten, J.; Witasse, O.; Simon, C.; Soldi-Lose, H.; Dutuit, O.; Thissen, R.; Alcaraz, C. Prediction of a $\mathrm{N}_{2}^{++}$ layer in the atmosphere of Titan. Geophys. Res. Lett. 2005, 32, L03203. [CrossRef]

33. Witasse, O.; Dutuit, O.; Lilensten, J.; Thissen, R.; Zabka, J.; Alcaraz, C.; Blelly, P.L.; Bougher, S.W.; Engel, S.; Andersen, L.H.; et al. Prediction of a $\mathrm{CO}_{2}{ }^{++}$layer in the atmosphere of Mars. Geophys. Res. Lett. 2002. [CrossRef]

34. Gronoff, G.; Lilensten, J.; Simon, C.; Witasse, O.; Thissen, R.; Dutuit, O.; Alcaraz, C. Modeling dications in the diurnal ionosphere of Venus. Astron. Astrophys. 2007, 465, 641-645. [CrossRef]

35. Lilensten, J.; Simon Wedlund, C.; Barthélémy, M.; Thissen, R.; Ehrenreich, D.; Gronoff, G.; Witasse, O. Dications and thermal ions in planetary atmospheric escape. Icarus 2013, 222, 169-187. [CrossRef] 
36. Blyth, R.R.; Delaunay, R.; Zitnik, M.; Krempasky, J.; Krempaska, R.; Slezak, J.; Prince, K.C.; Richter, R.; Vondracek, M.; Camilloni, R.; et al. The high resolution gas phase photoemission beamline, Elettra. J. Electron Spectrosc. Relat. Phenom. 1999, 101-103, 959-964. [CrossRef]

37. Alagia, M.; Candori, P.; Falcinelli, S.; Lavollèe, M.; Pirani, F.; Richter, R.; Stranges, S.; Vecchiocattivi, F. Dissociative double photoionization of $\mathrm{CO}_{2}$ molecules in the $36-49 \mathrm{eV}$ energy range: Angular and energy distribution of ion products. Phys. Chem. Chem. Phys. 2010. [CrossRef] [PubMed]

38. Alagia, M.; Candori, P.; Falcinelli, S.; Lavollée, M.; Pirani, F.; Richter, R.; Stranges, S.; Vecchiocattivi, F. Anisotropy of the angular distribution of fragment ions in dissociative double photoionization of $\mathrm{N}_{2} \mathrm{O}$ molecules in the 30-50 eV energy range. J. Chem. Phys. 2007. [CrossRef] [PubMed]

39. Lavollée, M. A new detector for measuring three-dimensional momenta of charged particles in coincidence. Rev. Sci. Instrum. 1990. [CrossRef]

40. Lundqvist, M.; Baltzer, P.; Edvardsson, D.; Karlsson, L.; Wannberg, B. Novel time of flight instrument for doppler free kinetic energy release spectroscopy. Phys. Rev. Lett. 1995, 75, 1058-1061. [CrossRef] [PubMed]

41. Field, A.; Eland, J.H.D. Lifetimes of metastable molecular doubly charged ions. Chem. Phys. Lett. 1993, 211, 436-442. [CrossRef]

42. Alagia, M.; Candori, P.; Falcinelli, S.; Mundim, K.C.; Mundim, M.S.; Pirani, F.; Richter, R.; Stranges, S.; Vecchiocattivi, F. Lifetime and kinetic energy release of metastable dications dissociation. Chem. Phys. 2012, 398, 134-141. [CrossRef]

43. Alagia, M.; Candori, P.; Falcinelli, S.; Mundim, M.S.P.; Pirani, F.; Richter, R.; Rosi, M.; Stranges, S.; Vecchiocattivi, F. Dissociative double photoionization of singly deuterated benzene molecules in the $26-33 \mathrm{eV}$ energy range. J. Chem. Phys. 2011. [CrossRef] [PubMed]

44. Alagia, M.; Callegari, C.; Candori, P.; Falcinelli, S.; Pirani, F.; Richter, R.; Stranges, S.; Vecchiocattivi, F. Angular and energy distribution of fragment ions in dissociative double photoionization of acetylene molecules at 39 eV. J. Chem. Phys. 2012. [CrossRef] [PubMed]

45. Brooke, T.Y.; Tokunaga, A.T.; Weaver, H.A.; Crovisier, J.; Bockelee-Morvan, D.; Crisp, D. Detection of acetylene in the infrared spectrum of comet Hyakutake. Nature 1996, 383, 606-608. [CrossRef] [PubMed]

46. Cernicharo, J.; Heras, A.M.; Pardo, J.R.; Tielens, A.G.G.M.; Pardo, J.R.; Herpin, F.; Guélin, M.; Waters, L.B.F.M. Infrared space observatory's discovery of $\mathrm{C}_{4} \mathrm{H}_{2}, \mathrm{C}_{6} \mathrm{H}_{2}$, and benzene in CRL 618. Astrophys. J. 2001, 546, L123-L126. [CrossRef]

47. Woods, P.M.; Millar, T.J.; Zijlstra, A.A.; Herbst, E. The synthesis of benzene in the proto-planetary Nebula CRL 618. Astrophys. J. 2002, 574, L167-L170. [CrossRef]

48. Skouteris, D.; Balucani, N.; Faginas-Lago, N.; Falcinelli, S.; Rosi, M. Dimerization of methanimine and its charged species in the atmosphere of Titan and interstellar/cometary ice analogs. Astron. Astrophys. 2015. [CrossRef]

49. Alagia, M.; Candori, P.; Falcinelli, S.; Lavollée, M.; Pirani, F.; Richter, R.; Stranges, S.; Vecchiocattivi, F. Double photoionization of $\mathrm{N}_{2} \mathrm{O}$ molecules in the 28-40 eV energy range. Chem. Phys. Lett. 2006, 432, 398-402. [CrossRef]

50. Brunetti, B.; Candori, P.; Falcinelli, S.; Lescop, B.; Liuti, G.; Pirani, F.; Vecchiocattivi, F. Energy dependence of the Penning ionization electron spectrum of $\mathrm{Ne}^{*}\left({ }^{3} \mathrm{P}_{2,0}\right)+\mathrm{Kr}$. Eur. Phys. J. D 2006, 38, 21-27. [CrossRef]

51. Cravens, T.E.; Robertson, I.P.; Waite, J.H., Jr.; Yelle, R.V.; Kasprzak, W.T.; Keller, C.N.; Ledvina, S.A.; Niemann, H.B.; Luhmann, J.G.; McNutt, R.L.; et al. Composition of Titan's ionosphere. Geophys. Res. Lett. 2006, 33, L07105. [CrossRef]

52. Franceschi, P.; Thissen, R.; Zabka, J.; Roithová, J.; Herman, Z.; Dutuit, O. Internal energy effects in the reactivity of $\mathrm{CO}_{2}{ }^{2+}$ doubly charged molecular ions with $\mathrm{CO}_{2}$ and CO. Int. J. Mass Spectrom. 2003, 228, 507-516. [CrossRef]

53. Alagia, M.; Candori, P.; Falcinelli, S.; Lavollée, M.; Pirani, F.; Richter, R.; Stranges, S.; Vecchiocattivi, F. Double photoionization of $\mathrm{CO}_{2}$ molecules in the 34-50 eV Energy range. J. Phys. Chem. A 2009, 113, 14755-14759. [CrossRef] [PubMed]

(C) 2016 by the authors; licensee MDPI, Basel, Switzerland. This article is an open access article distributed under the terms and conditions of the Creative Commons Attribution (CC-BY) license (http://creativecommons.org/licenses/by/4.0/). 